\title{
CONTRASSENSO NAS ESTIMATIVAS FUNDIÁRIAS PARA HABITAÇÃO SOCIAL ${ }^{1}$
}

\author{
Tomás Antonio Moreira ${ }^{2}$ \\ Joana Aparecida Zavaglia Mascarenhas \\ Torres Ribeiro ${ }^{3}$ \\ Gisela Cunha Viana Leonelli ${ }^{4}$
}

DOI: 10.5752/P.2316-1752.2017v24n34p106

\section{Resumo}

Valores pagos na aquisição de terra para habitação social sempre foram muito elevados e raramente as estimativas de custo estavam relacionadas às estimativas de terras necessárias para enfrentamento do déficit habitacional. A partir do Plano Nacional de Habitação, a viabilização de terra está condicionada à formulação de planos habitacionais e à sua articulação com instrumentos de política e planejamento urbano. As novas formulações não têm revelado muitos avanços em relação às estratégias anteriormente praticadas na trajetória da política habitacional e em especial da política fundiária. Frente à necessidade de maior compreensão das recentes formulações das políticas fundiárias, este artigo tem como objetivo analisar a estimativa de terras e a estimativa de custo para habitação de interesse social propostos em Planos de Habitação de Interesse Social de municípios da Região Metropolitana de Campinas. Como procedimentos metodológicos, adotou-se a análise dos cálculos da demanda por terra e a construção de quadros 
temáticos para a análise das estimativas de terra e custos. O trabalho permitiu identificar a fragilidade da abordagem da questão fundiária nos Planos Locais de Habitação de Interesse Social, tendo em vista o contrassenso nas estimativas de terras para sanear o déficit habitacional.

Palavras-chave: Planejamento Urbano. Política Fundiária. Política Habitacional. Plano Municipal de Habitação de Interesse Social. Região Metropolitana de Campinas.

1. Este artigo toma por base investigação em andamento "Avanços e Desafios de Planos Municipais de Habitação em Regiões Metropolitanas: o caso da RM de Campinas", financiada pelo CNPq - Processo: 485375/2013-3.

2. Arquiteto e Urbanista pela Pontifícia Universidade Católica de Campinas / Mestre em Ciências Aplicadas orientação Habitat \& Desenvolvimento pela Université Catholique de Louvain, PhD em Estudos Urbanos pela Université du Québec à Montréal. Professor do Instituto de Arquitetura e Urbanismo da Universidade de São Paulo. E-mail: tomas_moreira@sc.usp.br

3. Arquiteta e Urbanista pela Pontifícia Universidade Católica de Campinas / Mestre em Urbanismo pela Pontifícia Universidade Católica de Campinas. E-mail: joana.zavagliaribeiro@gmail.com

4. Arquiteta e Urbanista pelo Instituto de Arquitetura e Urbanismo da Universidade de São Paulo / Mestre em Urbanismo pela Pontifícia Universidade Católica de Campinas, Dra. em Arquitetura e Urbanismo pelo Instituto de Arquitetura e Urbanismo da Universidade de São Paulo. Professora da Faculdade de Engenharia Civil, Arquitetura e Urbanismo da Universidade Estadual de Campinas. E-mail: gisela@fec.unicamp.br 
NONSENSE IN THE LAND ESTIMATES FOR SO-

CIAL HOUSING

\section{Abstract}

Cash paid in the acquisition of land for social housing have always been very high and rarely cost estimates were related to estimates of land necessary to confront the housing deficit. From the National Housing Plan the feasibility of land is subject to the formulation of housing plans and their articulation with policy instruments and urban planning. New formulations have not revealed many advances over the strategies previously practiced in the trajectory of housing policy and in particular the land policy. Faced with the need for greater understanding of the recent formulation of land policies, this article aims to analyze the estimation of land and the cost estimate for social housing proposed in Social Housing Plans of the Campinas Metropolitan Area. As methodological procedures adopted the analysis of the calculations of demand for land and construction of thematic frameworks for the analysis of land and cost estimates. The work identified the weakness of the land issue approach within Local social housing, given the nonsense in the grounds of estimates to stabilize the housing deficit.

Keywords: Urban Planning. Policy Land. Housing Policy. Municipal Plan for Social Housing. Campinas Metropolitan Area.

\section{DISPARATES EN LAS ESTIMACIONES DE TIERRA PARA VIVIENDA SOCIAL}

\section{Resumen}

Los efectivos pagados en la adquisición de terrenos para viviendas sociales siempre han sido muy altos y pocas veces las estimaciones de costo se relacionan con las estimaciones de las tierras necesarias para enfrentar el déficit de vivienda. Desde el Plan Nacional de Vivienda la viabilidad de la tierra está sujeta a la formulación de los planes de vivienda y su articulación con los instrumentos de política y planificación urbana. Nuevas formulaciones no han revelado muchos avances sobre las estrategias previamente practicadas en la trayectoria de la política de vivienda y en particular de la política de tierras. Ante la necesidad de una mayor comprensión de la reciente formulación de políticas de suelo, este artículo tiene como objetivo analizar la estimación de la tierra y la estimación del costo de la vivienda social propuestas en los planes de Vivienda Social de municipalidades de la Región Metropolitana de Campinas. Como procedimientos metodológicos han sido adoptados el análisis de los cálculos de la demanda de tierras y la construcción de marcos temáticos para el análisis de las estimaciones de la tierra y de costos. El trabajo identifica la debilidad del enfoque de la cuestión del suelo, dado los disparates de las estimaciones de tierras para estabilizar el déficit de vivienda.

Palabras-claves: Planificación Urbana. Política del Suelo. Política de Vivienda. Plan Municipal de Vivienda Social. Región Metropolitana de Campinas. 


\section{Política fundiária na política habitacional brasileira}

No início dos anos 2000, uma nova composição da política habitacional passou a reger as diretrizes e os instrumentos para sua aplicação. Desde então, novos marcos legais foram instituídos, bem como a regulação local na elaboração, a implementação e a gestão de políticas habitacionais. Compõem esse novo marco legal institucional a Política Nacional de Habitação (PNH), o Sistema Nacional de Habitação (SNHIS), o Plano Nacional de Habitação (PLANHAB), assim como os Planos Estaduais e Municipais de Habitação de Interesse Social (PLHIS). Faz parte desse novo marco de regulação o Conselho das Cidades, no qual se inicia um processo participativo, por meio da realização das conferências municipais, estaduais e nacional das cidades e os processos participativos constituídos ao longo da elaboração dos Planos Diretores Municipais (PDM) e dos PLHIS (CARDOSO, MOREIRA, 2009; 2011; BRASIL, 2012).

A formulação da PNH partiu da concepção de uma dívida social acumulada no país, fruto das desigualdades sociais e da concentração de renda características da sociedade brasileira, juntamente com uma restrição histórica do acesso à terra e à moradia para a população de baixa renda (FERREIRA, 2005; MARICATO, 2006; AZEVEDO, 2007). A PNH definiu que as estratégias específicas de cada ente federado estariam expressas nos planos de habitação, documen- 
tos que passariam a representar as políticas habitacionais de cada nível de governo. Os planos estariam alinhados à PNH a partir das diretrizes estabelecidas pelo PLANHAB, formulado pela Secretaria Nacional de Habitação (SNH).

O PLANHAB procurou estabelecer propostas que levassem em conta a diversidade da problemática habitacional no país, as especificidades regionais e municipais, bem como as diferentes visões dos segmentos ligados ao setor da habitação (BONDUKI, 2008). Enquanto um instrumento da PNH, o PLANHAB teve como objetivo desenhar estratégias, tanto públicas quanto privadas, para o equacionamento do déficit habitacional. Para que fosse possível alterar substancialmente o quadro habitacional, essas estratégias deveriam incorporar ações simultâneas de longo, médio e curto prazo, considerando quatro eixos principais: financiamento e subsídios; arranjos e desenvolvimento institucional; cadeira produtiva da construção civil; e política fundiária urbana (BRASIL, 2009).

Em relação ao eixo da política fundiária, o PLANHAB elencou diretrizes que pudessem ser consideradas pelos governos municipais em suas políticas e ações, tendo-se dois objetivos principais: garantir acesso à terra urbanizada, legalizada e bem localizada para a provisão de HIS (unidades prontas ou lotes) na escala exigida pelas metas do PLANHAB; e regularizar os assentamentos informais, garantindo a permanência dos moradores de baixa renda (BRASIL, 2009). 
Em conjunção com a PNH, estabeleceu como princípios a implementação dos instrumentos e das diretrizes gerais da política urbana, dispostos pelo Estatuto da Cidade, visando garantir o cumprimento da função social da cidade e da propriedade, assim como o melhor ordenamento e controle do uso do solo, de forma a combater a retenção especulativa da terra e a viabilizar o seu acesso pela população de baixa renda.

Diversos municípios que compõem a Região Metropolitana de Campinas, localizada no Estado de São Paulo (RMC), elaboraram seus PLHIS, fomentando uma conjuntura para a articulação das políticas fundiária e habitacional (DENALDI, LEITÃO e AKAISHI, 2011). Entre 2007 e 2014, praticamente $80 \%$ dos municípios da RMC haviam concluído o processo de elaboração de seus PLHIS, sendo eles: Americana, Campinas, Cosmópolis, Hortolândia, Indaiatuba, Itatiba, Jaguariúna, Monte Mor, Nova Odessa, Pedreira, Santa Bárbara d'Oeste, Santo Antônio de Posse, Sumaré, Valinhos e Vinhedo. Cada município aderiu ao SNHIS a partir de 2006, de modo a contar com recursos do Fundo Nacional de Habitação de Interesse Social (FNHIS) para a implementação da política habitacional definida em seu PLHIS (BRASIL, 2005).

Entretanto essa conjuntura não se revelou favorável ao se constatar que a instrumentalização para uma política fundiária local se demonstrou deficitária. Um dos motivos 
que explicam esse quadro é que a disponibilização de recursos como dimensão estratégica para financiamento, subsídio e otimização da cadeia produtiva da construção civil teve como foco ampliar a participação da iniciativa privada nos processos de produção. Com isso, apostou-se no equacionamento da problemática habitacional por meio de estruturas privadas de obtenção da terra para a política pública.

Nessas estruturas, os lucros e os gastos fundiários têm peso significativo, o que coloca a terra urbana na linha de disputa de capitais, contrariando a dimensão estratégica de aplicação de uma política de solo que tenha como viés o controle social da apropriação da terra e a garantia de localizações que qualifiquem o acesso aos benefícios do processo formal de urbanização para a população de baixa renda. Nesse sentido, apesar das recentes diretrizes nacionais apresentarem um discurso que considerou a inclusão de uma nova política fundiária na $\mathrm{PNH}$, repetiram-se erros semelhantes aos praticados no passado, nos quais as ações de produção de moradias não foram acompanhadas de políticas de solo redistributivas, tendo contribuído para aprofundar o quadro de precariedade e segregação socioespacial nas cidades (AVILA, 2006; MOREIRA e RIBEIRO, 2016).

Para compreender o papel dos municípios da estruturação de uma política fundiária, tem-se como objetivo analisar a estimativa de terras e de custo para habitação de interesse 
social propostos nos Planos de Habitação de Interesse Social (PLHIS). Por meio da estimativa de terras e de seus custos, identificam-se as intensões, os conflitos e as contradições na promoção do direito à habitação no nível municipal. A pesquisa teve como recorte territorial seis dos vinte municípios que compõem a RMC: Americana, Campinas, Itatiba, Indaiatuba, Santa Barbara D'Oeste e Valinhos. Como procedimentos metodológicos, adotou-se a analise dos cálculos das estimativas de terra e de seus custos e foram construídos cinco quadros que focalizaram três categorias de análise: o déficit habitacional dos municípios, as demandas fundiárias da política de produção de moradias e as estratégias de ação propostas para aquisição das terras demandas pelo quadro habitacional evidenciado. Essas categorias foram colocadas à luz do período de planejamento proposto pelos PLHIS(s), bem como do contexto normativo e regulatório que permite ou impede a concretização do princípio da função social da propriedade para a democratização do acesso à terra. A partir desse conjunto de quadros, foram extraídos os elementos que discorrem sobre as estimativas de terra e de seus custos, de modo a inferir o quanto a abordagem fundiária está incorporada como proposição para o enfrentamento do déficit habitacional. 


\section{Abordagem da questão fundiária delineada no plano nacional de habitação}

O Sistema Nacional de Habitação (SNH) considera três aspectos fundamentais para uma abordagem adequada da questão fundiária para a HIS: o volume de terra necessário ao atendimento das demandas habitacionais acumuladas e futuras, o volume de recursos necessário a esse atendimento e o potencial fundiário existente e disponível nos municípios para a construção de novas moradias (DENALDI, 2009).

Em relação ao primeiro aspecto, o SNH recomenda como procedimento técnico a definição de uma fração ideal de terreno para cada domicílio. Uma vez definida a fração ideal, seu valor deve ser multiplicado pelo valor correspondente às necessidades habitacionais, tanto acumuladas como futuras. Dessa maneira é identificada a quantidade de terra exigida para enfrentamento da problemática estimada para o horizonte temporal dos PLHIS(s). A definição da fração ideal de terra está associada à definição da tipologia habitacional e dos parâmetros urbanísticos pensados para os projetos a serem empreendidos por meio das ações propostas pelos PLHIS(s). Para ambas as definições, os Planos podem tomar como referência os parâmetros de parcelamento e uso do solo já praticados nos municípios, em geral dispostos em legislações ou regulamentos específicos que estabelecem critérios diferenciados para HIS, 
como as Zonas Especiais de Interesse Social (ZEIS) ou as normas relativas à implantação de Empreendimentos de HIS (EHIS). Não obstante, os PLHIS(s) podem identificar a necessidade de elaboração de novos parâmetros habitacionais e urbanísticos, no intuito de permitir determinados empreendimentos, qualificá-los ou adequá-los às características das demandas a serem atendidas (DENALDI, 2009).

Em relação ao segundo aspecto a ser considerado na formulação de estratégias de ação, a SNH orienta que os PLHIS(s) devem estimar o volume geral de recursos necessário à sua produção. Com essa estimativa, torna-se possível definir como o município enfrentará sua problemática habitacional em termos financeiros, ponderando sua capacidade de investimento no setor e as fontes orçamentárias existentes e disponíveis nas demais esferas de governo. Para efeitos de cálculo, o custo total da produção habitacional deve considerar três componentes: o custo da construção da moradia, o custo da infraestrutura e o custo da terra. Como nem todos os municípios possuem estoque de terras públicas que pode ser disponibilizado para a política social de habitação, faz-se necessário calcular o custo das terras de propriedade privada, tendo-se em conta a compra ou a desapropriação como sua forma de obtenção (DENALDI, 2009). Para a estimativa dos custos de infraestrutura e de construção de moradias, a SNH orienta como referências os valores médios já utilizados pelos municípios em suas ações habitacionais; 
os parâmetros de custos apresentados no PLANHAB; e os valores de empréstimo ou transferência de recursos estabelecidos no âmbito dos programas habitacionais desenvolvidos pelo Governo Federal. No que se refere aos custos da terra, seu cálculo deve levar em consideração o preço médio do metro quadrado de terra urbanizada praticado em cada município, cuja referência pode partir tanto do valor venal utilizado pelo poder público para cálculo do Imposto Predial e Territorial Urbano (IPTU) quanto dos valores praticados no mercado de terrenos e imóveis (DENALDI, 2009).

Em relação ao terceiro aspecto, os municípios devem ter o conhecimento das condições em que ocorre a oferta habitacional, em especial as condições de acesso à terra e a disponibilidade de solo urbanizado. A SNH recomenda que os PLHIS(s) quantifiquem e qualifiquem as áreas aptas para a produção de HIS, a partir da definição de critérios que permitam sua delimitação e sua posterior destinação para atendimento das demandas acumuladas e futuras. A SNH e o PLANHAB consideram como áreas aptas: as terras vazias e urbanizadas delimitadas como ZEIS; as terras de propriedade pública ou privada, urbanizadas e adequadas à implantação de HIS; os domicílios vagos e os imóveis não utilizados ou subutilizados; loteamentos ou setores urbanos com grande percentual de lotes não ocupados; bem como as áreas já ocupadas por população de baixa renda, cuja diretriz de intervenção corresponde à remoção e re- 
construção de unidades habitacionais na própria área do assentamento (MCIDADES, 2008; MCIDADES, 2010; DENALDI, 2009). As áreas aptas devem ser delimitadas e caracterizadas nos PLHIS(s), para que a formulação de estratégias de ação seja feita de forma apropriada. Elas devem ser mapeadas em quantidade suficiente para atendimento dos domicílios correspondentes ao déficit acumulado e à demanda futura priorizada no horizonte temporal dos Planos (DENALDI, 2009).

\section{Estimativa de terras para habitação de interes- se social na Região Metropolitana de Campinas}

No que se refere ao conceito de déficits habitacionais e ao primeiro aspecto colocado pelo $\mathrm{SNH}$ - a estimativa de terras para produção de Habitação de Interesse Social (HIS) -, os municípios analisados da Região Metropolitana de Campinas podem ser organizados em três grupos: municípios que estimam o volume de terra necessário ao atendimento do conjunto de suas necessidades habitacionais - Campinas e Itatiba; municípios que realizam a estimativa de terra apenas para a demanda a ser atendida - Americana e Santa Bárbara d'Oeste; e municípios que não estimam o volume de terra para atendimento das demandas habitacionais - Valinhos.

Nos grupos cujos municípios estimaram, total ou parcialmente, o volume de terras para HIS, a estimativa consid- 
erou as diretrizes sugeridas pela SNH no que diz respeito à definição da fração ideal e das tipologias habitacionais a serem adotadas nos empreendimentos. Dessa forma, para estimar as necessidades fundiárias da produção de HIS, os PLHIS(s), estabeleceram diferentes cotas de terreno para cada domicílio, considerando a possibilidade de implantação de diferentes tipologias habitacionais e a constituição de cenários que pudessem atender à diversidade das demandas identificadas.

Em relação às frações ideais de terra, Campinas e Itatiba adotaram cotas brutas de terreno, cujos critérios foram estabelecidos a partir da previsão de uma reserva de áreas não edificáveis. Essa reserva se justifica pelo fato de muitos terrenos poderem apresentar áreas de proteção ambiental ou alguma restrição à urbanização (PMC, 2011), assim como serem necessários para a implantação de sistemas viários e de equipamentos públicos e de lazer (PMIT, 2011ab).

Nos demais municípios que estimaram as necessidades fundiárias, a definição tomou como critério os parâmetros estabelecidos pelas legislações urbanísticas locais, em especial o Plano Diretor e as leis de parcelamento, uso e ocupação do solo. Americana utilizou as normas urbanísticas impostas tanto para as Zonas Especiais de Interesse Social (ZEIS) como para as zonas com permissão de uso residencial; Santa Bárbara d'Oeste usou o lote mínimo legalmente instituído no município; Indaiatuba aproveitou o "lote pa- 
drão" das zonas de uso onde se permite HIS (Tabela 1).

No caso de Valinhos, embora o PLHIS tenha identificado as frações ideais de terra e as tipologias habitacionais a serem adotadas, não há uma estimativa do volume fundiário total necessário ao atendimento das demandas. Ressalta-se que as frações e seus critérios foram indicados no âmbito da definição dos custos das unidades habitacionais ao se tratar dos recursos estimados para HIS pelos PLHIS(s).

Em todos os municípios analisados, embora os critérios de definição das tipologias habitacionais tivessem como objetivo atender à diversidade característica das demandas locais, a definição dos parâmetros da unidade de moradia esteve associada às referências existentes e disponíveis para cálculo da estimativa dos custos da produção. Os PLHIS(s) estabeleceram, portanto, critérios de atendimento a partir de diferentes tipos de unidade habitacional, levando-se em conta parâmetros de área construída cujos custos já tivessem sido estabelecidos por outros órgãos ou instituições ligadas ao setor habitacional. Campinas e Indaiatuba estabelecem parâmetros construtivos e de custo similares para suas tipologias (Tabela 1), tendo como referência adotada o Programa Minha Casa, Minha Vida (PMCMV), que estipula 45-48 metros quadrados para as unidades habitacionais, sejam elas verticais ou horizontais.

A partir das frações ideais e tipologias adotadas, os PLHIS estimaram a necessidade de mais de 20 milhões de met- 


\begin{tabular}{|c|c|c|c|c|c|c|}
\hline \multicolumn{7}{|c|}{ Critérios e referências adotados pelos PLHIS(s) para a estimativa de terras para HIS } \\
\hline \multirow[b]{2}{*}{$\begin{array}{l}\text { Munic } \\
\text { ipios } \\
\text { anslis } \\
\text { ados }\end{array}$} & \multicolumn{2}{|c|}{ Fraçẩo ideal de terra } & \multicolumn{4}{|c|}{ Tipologia habitacional } \\
\hline & Critérios & $\begin{array}{l}\text { Paràmeitros } \\
\qquad\left(m^{2}\right)\end{array}$ & $\begin{array}{l}\text { Critérios uniclade } \\
\text { habiliacional }(\mathrm{UH})\end{array}$ & $\begin{array}{l}\text { Parâm } \\
\text { etros } \\
\left\langle\mathrm{m}^{2}\right\rangle\end{array}$ & $\begin{array}{c}\text { Custo } \\
\text { UH com } \\
\text { infraestr } \\
\text { Utura' }\end{array}$ & Referèncias \\
\hline \multirow{3}{*}{$\begin{array}{l}\text { Ameri } \\
\text { cans }\end{array}$} & \multirow{3}{*}{$\begin{array}{l}\text { Plano Diretor, } \\
\text { Lei de } \\
\text { zoneamento } \\
\text { /ZEIS; zonss } \\
\text { com permissaso } \\
\text { de uso } \\
\text { residencial }\end{array}$} & $150 \mathrm{~m}^{2}$ & $\begin{array}{c}\text { "Embriāo" em lote } \\
\text { urbanizado }\end{array}$ & - & $\begin{array}{c}\text { RS } \\
24.000,0 \\
0\end{array}$ & $\begin{array}{c}\text { Sistema } \\
\text { Nacional de } \\
\text { Pesquisa de } \\
\text { Custos e } \\
\text { Indices da } \\
\text { Consiruçăo } \\
\text { Civil (SINA.PI) }\end{array}$ \\
\hline & & $85 \mathrm{~m}^{2}$ & $\begin{array}{c}\text { Horizontal } \\
\text { (sobreposta) }\end{array}$ & - & $\begin{array}{c}\text { RS } \\
38.000,0 \\
0\end{array}$ & $\begin{array}{l}\text { Cooperativa } \\
\text { Nacional da } \\
\text { Habitaşäo e } \\
\text { Consiruçăa } \\
\text { (COOPERTET } \\
\text { O) }\end{array}$ \\
\hline & & $60 \mathrm{~m}^{2}$ & $\begin{array}{c}\text { Vertical } \\
\text { (apartamento) }\end{array}$ & $51 \mathrm{~m}^{2}$ & $\begin{array}{c}\text { RS } \\
51.500,0 \\
0\end{array}$ & \\
\hline \multirow{2}{*}{$\begin{array}{l}\text { Camp } \\
\text { inas }\end{array}$} & \multirow{2}{*}{ 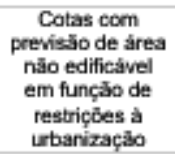 } & $\begin{array}{c}250 \mathrm{~m}^{2} \\
\text { (cota trusta) }\end{array}$ & $\begin{array}{c}\text { Horizontal (casa } \\
\text { terrea) }\end{array}$ & $48 \mathrm{~m}^{2}$ & $\begin{array}{l}\text { RS } \\
48.000,0 \\
0\end{array}$ & \multirow[b]{2}{*}{ PMCMV } \\
\hline & & $\begin{array}{l}125 \mathrm{~m}^{2} \\
\text { (cota } \\
\text { liquida) }\end{array}$ & $\begin{array}{l}\text { Vertical (casa } \\
\text { sobreposta / } \\
\text { apartamento) }\end{array}$ & $48 \mathrm{~m}^{2}$ & $\begin{array}{c}\text { RS } \\
52.000,0 \\
0\end{array}$ & \\
\hline \multirow{3}{*}{$\begin{array}{l}\text { Indaia } \\
\text { tuba }\end{array}$} & \multirow{3}{*}{$\begin{array}{l}\text { Lei de } \\
\text { zoneamento/ } \\
\text { zonas com } \\
\text { permissäo de } \\
\text { HIS }\end{array}$} & \multirow{3}{*}{$\begin{array}{l}\text { "lote } \\
\text { padrăo" }\end{array}$} & $\begin{array}{l}\text { Horizontal (casa } \\
\text { térrea) }\end{array}$ & $48 \mathrm{~m}^{2}$ & $\begin{array}{c}\text { RS } \\
48.000,0 \\
0\end{array}$ & \multirow{3}{*}{$\begin{array}{l}\text { PMCMV f } \\
\text { Prefeitura } \\
\text { Municipal }\end{array}$} \\
\hline & & & 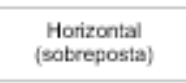 & $44 \mathrm{~m}^{2}$ & $\begin{array}{c}\text { RS } \\
51.000,0 \\
0 \\
\end{array}$ & \\
\hline & & & $\begin{array}{c}\text { Vertical } \\
\text { (apartamento) }\end{array}$ & $44 \mathrm{~m}^{2}$ & $\begin{array}{c}\text { RS } \\
65.000,0 \\
0\end{array}$ & \\
\hline \multirow[b]{2}{*}{ Ha:ba } & \multirow{2}{*}{$\begin{array}{c}\text { Cotas com } \\
\text { previsajo de ârea } \\
\text { para } \\
\text { implantaçäso de } \\
\text { sistema viário e } \\
\text { equipamentos }\end{array}$} & $\begin{array}{c}250 \mathrm{~m}^{2} \\
\text { (cota bruta) }\end{array}$ & $\begin{array}{c}\text { Horizontal (casa } \\
\text { terrea) }\end{array}$ & $45 \mathrm{~m}^{2}$ & $\begin{array}{c}\text { RS } \\
45.000,0 \\
0 \\
\end{array}$ & \multirow{2}{*}{$\begin{array}{l}\text { SNH / Plano } \\
\text { Nacional de } \\
\text { Habitaçăo } \\
\text { (PLANHAB) }\end{array}$} \\
\hline & & $\begin{array}{c}125 \mathrm{~m}^{2} \\
\text { (cota } \\
\text { liquida) }\end{array}$ & $\begin{array}{c}\text { Horizontal } \\
\text { Vertical } \\
\text { (casa sabreposta } \\
\text { / apartamento) }\end{array}$ & $45 \mathrm{~m}^{2}$ & $\begin{array}{c}\text { RS } \\
50.000,0 \\
0\end{array}$ & \\
\hline \multirow{3}{*}{$\begin{array}{l}\text { Santa } \\
\text { Barta } \\
\text { ra } \\
\text { d'Oes } \\
\text { te }\end{array}$} & \multirow{3}{*}{$\begin{array}{l}\text { Lei de } \\
\text { Parcelamento / } \\
\text { lose minimo } \\
\text { permitido no } \\
\text { municipio }\end{array}$} & $175 \mathrm{~m}^{2}$ & $\begin{array}{c}\text { "Embriào" em lote } \\
\text { urbanizado }\end{array}$ & $33 \mathrm{~m}^{2}$ & $\begin{array}{c}\text { RS } \\
38.000,0 \\
0\end{array}$ & \multirow{3}{*}{$\begin{array}{c}\text { Sistema } \\
\text { Nacional de } \\
\text { Pesquisa de } \\
\text { Custos e } \\
\text { Indices da } \\
\text { Construçăo } \\
\text { Civil (SINAPI) }\end{array}$} \\
\hline & & $140 \mathrm{~m}^{2}$ & $\begin{array}{l}\text { Horizontal } \\
\text { (sobreposta } \\
\text { geminada) }\end{array}$ & $42 \mathrm{~m}^{2}$ & $\begin{array}{c}\text { RS } \\
47.000,0 \\
0\end{array}$ & \\
\hline & & $80 \mathrm{~m}^{2}$ & $\begin{array}{c}\text { Vertical } \\
\text { (apartamento) }\end{array}$ & $37 \mathrm{~m}^{2}$ & $\begin{array}{c}\text { RS } \\
34.000,0 \\
0\end{array}$ & \\
\hline \multirow{2}{*}{$\begin{array}{l}\text { Valinh } \\
\text { os }\end{array}$} & \multirow[b]{2}{*}{. } & $\begin{array}{c}200 \mathrm{~m}^{2} \text { (lote } \\
\text { minimo) }\end{array}$ & Horizontal & - & $\begin{array}{c}\text { RS } \\
63.300,0 \\
0\end{array}$ & \multirow{2}{*}{$\begin{array}{l}\text { Portal da } \\
\text { Construç.jo } \\
\text { (PINI Web) }\end{array}$} \\
\hline & & $\begin{array}{l}600 \mathrm{~m}^{2} \text { (bte } \\
\text { minimo) }\end{array}$ & Vertical & $\cdot$ & $\begin{array}{c}\text { RS } \\
62.800,0\end{array}$ & \\
\hline \multicolumn{7}{|c|}{$\begin{array}{l}\text { *Valores médios correspondentes ao ano de elaboração dos Diagnósticos dos PLHIS(s). } \\
\text { Fonte: elaborado pelos autores, a partir do Diagnóstico Habitacional dos PLHIS(s) dos municípios } \\
\text { analisados (PMA, 2008a; PMC, 2009; PMI, 2010; PMIT, 2011; PMSOB, 2011; PMV, 2012). }\end{array}$} \\
\hline
\end{tabular}

Tabela 1 - Critérios e referências adotados pelos PLHIS(s) para a estimativa de terras para HIS. Fonte: Elaborado pelos autores. 
ros quadrados de terra para atendimento das demandas por HIS. Entretanto, essas demandas representam 76\% do que representam seus déficits habitacionais, segundo o conceito adotado pelo PNH (Tabela 2).

\begin{tabular}{|c|c|c|c|c|c|c|c|c|c|c|}
\hline \multirow{3}{*}{$\begin{array}{l}\text { Municípios } \\
\text { analisados }\end{array}$} & \multicolumn{10}{|c|}{ Estimativa de terra para atendimento das necessidades e demandas habitacionais } \\
\hline & \multicolumn{5}{|c|}{ Componentes das necessidades habitacionais } & \multicolumn{2}{|c|}{$\begin{array}{c}\text { Demandas a serem } \\
\text { atendidas }\end{array}$} & \multicolumn{3}{|c|}{ Estimativa de terra } \\
\hline & \multicolumn{2}{|c|}{$\begin{array}{c}\text { Deficit } \\
\text { habitacional (Dh) }\end{array}$} & \multicolumn{2}{|c|}{ Demanda futura (Df) } & \multirow{2}{*}{$\begin{array}{c}\begin{array}{c}\text { Total } \\
(\mathrm{PNH})^{2}\end{array} \\
15.477\end{array}$} & \multirow{2}{*}{$\begin{array}{c}\begin{array}{c}\text { Total } \\
\text { (PLHIS) }\end{array} \\
5.183\end{array}$} & \multirow{2}{*}{$\begin{array}{c}\begin{array}{c}\% / \\
\text { component } \\
\text { es }\end{array} \\
33,5 \%\end{array}$} & Total $\left(m^{2}\right)$ & \multicolumn{2}{|c|}{$\begin{array}{l}\text { Demanda de } \\
\text { atendimento }\end{array}$} \\
\hline Americana & \multicolumn{2}{|c|}{7.301} & $\begin{array}{c}4.539 \\
\text { estimada } \\
1\end{array}$ & $\begin{array}{l}8.178^{3} \\
\text { estimada } \\
2\end{array}$ & & & & 701.137 & \multicolumn{2}{|c|}{5.183} \\
\hline Campinas & \multicolumn{2}{|c|}{30.871} & \multicolumn{2}{|c|}{33.515} & 64.386 & 65.000 & $101,0 \%$ & $15.989 .250,00^{4}$ & \multicolumn{2}{|c|}{$63.857^{4}$} \\
\hline Indaiatuba & \multicolumn{2}{|c|}{10.832} & \multicolumn{2}{|r|}{ - } & $13.855^{5}$ & 7.709 & $55,2 \%$ & 440.000 & \multicolumn{2}{|c|}{7.709} \\
\hline |tatiba & $\begin{array}{c}2.302 \\
\text { adotado } \\
1\end{array}$ & $\begin{array}{c}2.333 \\
\text { adotado } \\
2\end{array}$ & $\begin{array}{l}6.552 \\
\text { estimada }\end{array}$ & $\begin{array}{l}3.256 \\
\text { adotada }\end{array}$ & 8.885 & 5.609 & $63,1 \%$ & $\begin{array}{cc}1.952 .75 & \\
0^{4} & \\
\text { estimado } & 1.971 .500 \\
D h & 4 \\
\text { adotado } & \text { adotado } \\
1 & \end{array}$ & $\begin{array}{c}8.854^{4} \\
\text { Dh } \\
\text { adotado } 1 \\
\text { + Df } \\
\text { estimada }\end{array}$ & $\begin{array}{c}8.443^{4} \\
\text { Dh adotado } \\
2+\mathrm{Df} \\
\text { estimada }\end{array}$ \\
\hline $\begin{array}{l}\text { Santa Bàrbara } \\
\text { d'Oeste }\end{array}$ & \multicolumn{2}{|c|}{10.294} & \multicolumn{2}{|c|}{2.450} & 12.744 & 9.026 & $70,8 \%$ & 970.250 & \multicolumn{2}{|c|}{9.026} \\
\hline Valinhos & \multicolumn{2}{|c|}{6.085} & \multicolumn{2}{|r|}{ 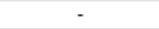 } & $8.042^{5}$ & 3.148 & $34,8 \%$ & - & \\
\hline Total & \multicolumn{2}{|c|}{$87.726^{6}$} & \multicolumn{2}{|c|}{$50.693^{\circ}$} & 124.489 & 95.875 & $76,8 \%$ & $20.072 .137^{4}$ & \multicolumn{2}{|c|}{$94.318^{5}$} \\
\hline \multicolumn{11}{|c|}{ 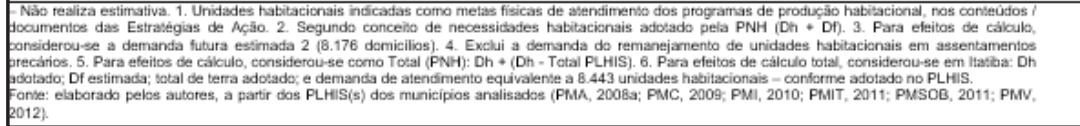 } \\
\hline
\end{tabular}

Tabela 2 - Estimativa de terra para atendimento das necessidades e demandas habitacionais. Fonte: Elaborado pelos autores.

Campinas apresenta a maior necessidade fundiária do conjunto. Isso se deve ao fato de ela concentrar o maior déficit habitacional, a maior demanda futura por novas moradias e pelo fato de considerar ambos os componentes para o cálculo da estimativa de terra.

Itatiba, que embora apresente a segunda maior necessidade de terra, não concentra os maiores déficits habitacionais, mas, sim, a menor de todo o conjunto. Indaiatuba, Santa Bárbara d'Oeste e Americana apresentam déficits bem mais expressivos, embora suas necessidades fundiárias 
estejam abaixo das necessidades de Itatiba. Essas diferenças se dão pelo fato de esses três municípios não terem considerado, para a estimativa de terra, o total de seus déficits habitacionais, mas, sim, as demandas previstas para serem atendidas pelo poder público.

No caso de Americana, observa-se, pela Tabela 2, que a estimativa de terra apresentada no PLHIS abrange apenas $33,5 \%$ do total de suas necessidades. O PLHIS informa que o município precisa de cerca de 700 mil metros quadrados de terra para atender pouco mais de cinco mil domicílios no decorrer de seu horizonte temporal (2009-2020). Entretanto, somente seu déficit habitacional compreende mais de sete mil domicílios. O município apresentou a estimativa de terra na etapa das Estratégias de Ação e não na fase de Diagnóstico Habitacional. A abordagem fundiária é, portanto, realizada no intuito de se verificar o potencial existente e disponível e não com o objetivo de se estimar as necessidades fundiárias das demandas habitacionais.

No caso de Itatiba, o PLHIS apresenta duas referências numéricas para o volume de terras demandadas para atendimento de suas necessidades habitacionais - uma na fase de Diagnóstico e outra na fase das Estratégias de Ação. Essas divergências podem estar relacionadas tanto a decisões políticas quanto a questões técnicas. Decisão política no sentido de se adotar, no caso da demanda futura, a referência que o poder público se propõe a atender 
nos programas de ação; e questão técnica no sentido das divergências poderem estar associadas a uma revisão dos conteúdos do produto do Diagnóstico, para a formulação das Estratégias de Ação.

Em Santa Bárbara d'Oeste, a estimativa do volume de terras é feita sobre a demanda, a qual representa $70 \%$ das necessidades habitacionais do município e a ela correspondem os domicílios que compõem a coabitação e os imóveis cedidos, bem como a demanda futura situada nas faixas de renda de zero a três salários mínimos. Considerando esse percentual, o PLHIS desenvolve três estudos para cálculo das necessidades e custos da terra e da produção habitacional, apontando cenários de atendimento segundo combinações entre as diferentes frações e tipologias habitacionais que foram definidas. Levando-se em conta essa combinação, o PLHIS estima a necessidade de $970.250 \mathrm{~m} 2$ de terra para atender à demanda priorizada pelo poder público. No entanto, o PLHIS informa a necessidade de reservar um percentual de terras para a implantação de sistemas de áreas livres públicas e de áreas institucionais, o que implica na redução de $50 \%$ do volume de terras para produção habitacional (SOB, 2011, p. 78-80). Considerando a perda percentual de áreas, o volume de terra identificado pelo PLHIS de Santa Bárbara atenderá, portanto, não a 70\%, mas a $35 \%$ do déficit habitacional do município.

As análises expostas mostram uma grande fragilidade dos 
PLHIS(s) no tocante à abordagem da estimativa de terra e sua relação com o levantamento das problemáticas habitacionais.

\section{Estimativa de custos da terra para habitação de interesse social}

Todos os municípios tratam do volume de recursos necessários à aquisição de terra e à produção habitacional. $\mathrm{O}$ que os diferencia é a forma de abordagem da questão ou a sua abrangência em relação ao enfrentamento do déficit habitacional. Os municípios podem ser organizados em três grupos: municípios que estimam os recursos necessários ao atendimento do déficit habitacional - Campinas e Itatiba; municípios que estimam recursos apenas para as demandas a serem atendidas - Americana, Indaiatuba e Santa Bárbara d'Oeste; e municípios que estimam os custos isolados da terra e das diferentes tipologias habitacionais adotadas, mas que não os consolidam, não possibilitando identificar o volume global de recursos necessários ao atendimento das demandas por novas moradias - Valinhos.

Levando-se em conta as especificidades da identificação dos custos da terra, os municípios podem ser organizados em três outros subgrupos (Tabela 3): (A) municípios que informam os custos da terra segundo a localização de terras para HIS (Americana e Valinhos); (B) municípios que informam o custo da terra segundo uma média do preço 
do metro quadrado (Indaiatuba, Itatiba e Santa Bárbara d'Oeste); e (C) municípios que não informam o custo da terra (Campinas).

Pela Tabela 3, é possível visualizar as disparidades do preço do metro quadrado da terra entre os diferentes municípios. Em Americana e Valinhos, as áreas centrais possuem maiores custos de terra, não apenas em relação às áreas periféricas, mas, também, em relação aos custos de terra dos demais municípios. Por sua vez, as áreas periféricas e as ZEIS de Americana concentram preços fundiários muito

\begin{tabular}{|c|c|c|c|c|c|c|}
\hline \multicolumn{7}{|c|}{$\begin{array}{l}\text { Critérios e referéncias adotados pelos PLHIS(s) para a estimativa de custos da terra para } \\
\text { HIS }\end{array}$} \\
\hline \multirow{2}{*}{$\begin{array}{l}\text { Sub } \\
\text { grupo }\end{array}$} & \multirow{2}{*}{$\begin{array}{l}\text { Municipio } \\
\text { s } \\
\text { analisado } \\
\text { s }\end{array}$} & \multirow[b]{2}{*}{ Critérios } & \multirow[b]{2}{*}{ Referência } & \multicolumn{3}{|c|}{ Terra } \\
\hline & & & & \multicolumn{2}{|c|}{ Localizaçẩo } & $\begin{array}{l}\text { Custai } \mathrm{m}^{2} \\
\text { (R\$) }\end{array}$ \\
\hline \multirow{10}{*}{ A } & \multirow{4}{*}{$\begin{array}{l}\text { American } \\
\text { a }\end{array}$} & \multirow{4}{*}{$\begin{array}{l}\text { Valores de solo } \\
\text { ubano, segundo } \\
\text { localizaçẩo e } \\
\text { dimensấo das } \\
\text { glebas aptas para } \\
\text { HIS }\end{array}$} & \multirow{4}{*}{$\begin{array}{c}\text { Planta de } \\
\text { Valores Reais / } \\
\text { Prefeitura }\end{array}$} & \multicolumn{2}{|c|}{$\begin{array}{l}\text { Perimeito central } \\
\quad<10.000 \mathrm{~m}^{2}\end{array}$} & 336,00 \\
\hline & & & & Peri & $\begin{array}{l}\text { imeito central } \\
10.000 \mathrm{~m}^{2}\end{array}$ & 158,20 \\
\hline & & & & & IS de vazios & 38,00 \\
\hline & & & & Are: & as periféricas & 36,58 \\
\hline & \multirow{6}{*}{ Valinhos } & \multirow{6}{*}{$\begin{array}{l}\text { Valores de solo } \\
\text { urbano, segundo } \\
\text { localização de } \\
\text { terras }\end{array}$} & \multirow{6}{*}{ Prefeitura } & \multirow{3}{*}{ 蛋 } & São Cristóvăo & 231,52 \\
\hline & & & & & Santa Cruz & 250,00 \\
\hline & & & & & Santana & 186,74 \\
\hline & & & & \multirow{3}{*}{ g⿺辶大 } & Santa Elisa & 130,00 \\
\hline & & & & & Espirito Santo & 150,00 \\
\hline & & & & & $\begin{array}{c}\text { Santa } \\
\text { Escolastica }\end{array}$ & 160,00 \\
\hline \multirow{3}{*}{ B } & Indaiatuba & \multirow{3}{*}{$\begin{array}{l}\text { Média do preço do } \\
m^{2} \text { de terra }\end{array}$} & 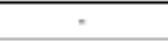 & & r & 45,00 \\
\hline & Itattoa & & Prefeitura & & $=$ & 100,00 \\
\hline & $\begin{array}{l}\text { Santa } \\
\text { Bárbara } \\
\text { d'Oeste } \\
\end{array}$ & & $\begin{array}{l}\text { Pesquisa com } \\
\text { setor } \\
\text { imobiliário local } \\
\end{array}$ & & $=$ & 100,00 \\
\hline $\mathrm{C}$ & Campinas & 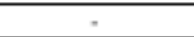 & . & & $r$ & . \\
\hline $\begin{array}{l}\text { Niso } \\
\text { anse: }\end{array}$ & $\begin{array}{l}\text { aloza estimat } \\
\text { laborado pel } \\
\text { MI, 2010; PM }\end{array}$ & $\begin{array}{l}\text { utores, a partir doe } \\
011 ; \text { PMSOB, } 201\end{array}$ & $\begin{array}{l}\text { LHIS(s) dos mi } \\
\text { PMV, 2012). }\end{array}$ & inging & analisados (P) & 2008a; PMC \\
\hline
\end{tabular}

Tabela 3 - Critérios e referências adotados pelos PLHIS(s) para a estimativa de custos da terra para HIS. Fonte: Elaborado pelos autores. 
mais baixos do que as áreas periféricas de Valinhos, as quais apresentam valores de terra superiores à média dos custos praticados em Itatiba e Santa Bárbara d'Oeste, por exemplo, onde o valor da terra é relativamente similar. Em Indaiatuba, a média de custos de terra segue os custos das ZEIS de Americana, ou seja, apresenta um dos valores mais baixos dentre os seis municípios.

Na maioria dos municípios, os preços fundiários foram embasados em referenciais de valores adotados pelo poder público, à exceção de Santa Bárbara d'Oeste e Americana - que adotaram referenciais praticados no mercado de imóveis - e Campinas, que não realizou a estimativa dos custos da terra, embora tenha estimado o total de recursos necessários ao atendimento do conjunto de suas necessidades habitacionais.

No caso de Indaiatuba, cujo PLHIS adota para cálculo dos custos da produção os valores praticados pelo PMCMV (BRASIL, 2009; CEF, 2009), há a estimativa dos custos necessários à obtenção da terra. Diferentemente de Campinas, essa estimativa considera apenas a demanda a ser atendida e não o conjunto do déficit habitacional. O PLHIS de Indaiatuba é um dos que não se apropriou do conceito de déficit, não incorporou informações sobre a demanda futura e, em decorrência, a estimativa da quantidade de terra abrangeu apenas $55 \%$ do que seriam as demandas reais do município. A estimativa dos custos da terra se deu, 
portanto, sobre esse percentual, resultando um volume de recursos $45 \%$ inferior ao que seria realmente necessário.

Inserido no subgrupo de municípios que estimam o custo da terra a partir do preço médio do metro quadrado, Indaiatuba estima ser necessário mais de $\mathrm{R} \$ 19.000 .000,00$ para a compra dos 440 mil metros quadrados de terra demandados pela população beneficiária do PLHIS. Esse valor representa cerca de $4 \%$ dos custos totais estimados para a produção habitacional, tomando-se como base a média de $\mathrm{R} \$ 45,00$ por metro quadrado de terra. Esse percentual dos custos da terra em relação aos custos totais da produção se coloca bem abaixo dos valores evidenciados nos outros municípios.

Em Santa Bárbara d'Oeste e Itatiba, por exemplo, cujo preço médio da terra gira em torno de $R \$ 100,00 / m 2$, o percentual dos custos fundiários em relação aos custos totais da produção atinge mais de 20\% (Tabela 4).

Embora o município de Itatiba se enquadre no grupo cuja estimativa do volume de terra e de recursos envolveu todo o conjunto do déficit habitacional, os custos totais do componente terra foram calculados apenas para parte do déficit, uma vez que o município já dispunha de um banco de terras públicas. Além desse banco de terras, dimensionado em $156.000 \mathrm{~m} 2$, o PLHIS considerou que $316.750 \mathrm{~m} 2$ de terrenos poderiam ser obtidos por meio do instrumento da dação em pagamento, pelo fato de apresentarem dívi- 


\begin{tabular}{|c|c|c|c|c|c|c|c|c|c|}
\hline \multirow[b]{4}{*}{$\begin{array}{l}\text { Municipi } \\
\text { os } \\
\text { Analisad } \\
\text { os }\end{array}$} & \multicolumn{8}{|c|}{ Estimativa de custos para atendimento das necessidades e demandas habitacionais } & \multirow{4}{*}{$\begin{array}{c}\text { Demanda } \\
\text { das } \\
\text { estimativa } \\
5 \text { de } \\
\text { custos }\end{array}$} \\
\hline & \multicolumn{4}{|c|}{ Necessidades habitacionais } & \multicolumn{4}{|c|}{ Estimativas de terra e custos } & \\
\hline & \multicolumn{2}{|c|}{ Componentes } & \multicolumn{2}{|c|}{ A serem atendidas' } & \multicolumn{2}{|c|}{ Terra } & \multicolumn{2}{|c|}{ Produçăo habitacional } & \\
\hline & $\begin{array}{c}\text { Deficit } \\
\text { habitacional } \\
\text { (Dh) }\end{array}$ & $\begin{array}{l}\text { Demanda } \\
\text { futura (Df) }\end{array}$ & Total & $\begin{array}{c}\% / \\
\text { Componen } \\
\text { tes }\end{array}$ & Total $\left(m^{2}\right)$ & Custo total (R\$) & $\begin{array}{l}\text { Custo global } \\
(\mathrm{RS})\end{array}$ & $\begin{array}{l}\text { \% Custo } \\
\text { terra / } \\
\text { Custo } \\
\text { global }\end{array}$ & \\
\hline \multirow{3}{*}{$\begin{array}{l}\text { America } \\
\text { na } \\
\text { Campina } \\
5 \\
\text { Indaiatub } \\
\text { a } \\
\end{array}$} & 7.301 & $4.539^{8.176}$ & 5.183 & $33,5 \%{ }^{2}$ & 701.137 & $52.702 .087,78$ & 188.185.858,81 & $26,6 \%$ & 5.183 \\
\hline & 30.871 & 33.515 & 65.000 & $101,0 \%$ & $15.889 .250,00$ & - & $\begin{array}{c}3.197 .850 .000,0 \\
0^{3}\end{array}$ & $\cdot$ & $63.957^{3}$ \\
\hline & 10.832 & - & 7.709 & $55,2 \%^{4}$ & 440.000 & $18.800 .000,00$ & $505.723 .000,00$ & $3,9 \%$ & 7.709 \\
\hline Itatiba & $\begin{array}{c}2.333 \\
\text { (adotado) }\end{array}$ & $\begin{array}{c}6.552 \\
\text { (estimada) }\end{array}$ & 5.609 & $63,1 \%$ & $\begin{array}{l}1.971 .500^{3} \\
\text { (adotado) }\end{array}$ & $149.875 .000,00^{7}$ & $604.788 .698,00^{6}$ & $24,8 \%$ & $\begin{array}{c}8.443^{\circ} \\
\text { (Dh } \\
\text { adotado + } \\
\text { Df } \\
\text { estimada) }\end{array}$ \\
\hline $\begin{array}{l}\text { S. } \\
\text { Bárbara } \\
\text { d'Oeste }\end{array}$ & 10.294 & 2.450 & 9.026 & $70,8 \%$ & 970.250 & $97.025 .000,00$ & $436.906 .002,94$ & $22,2 \%$ & 9.028 \\
\hline Valinhos & 6.095 & - & 3.148 & $34,8 \%{ }^{4}$ & - & - & - & - & - \\
\hline Total & 67.726 & 50.693 & 85.675 & $76,8 \%$ & 20.072 .137 & $319.402 .087,78$ & $\underset{5}{4.943 .443 .559,8}$ & - & 94.318 \\
\hline \multicolumn{10}{|c|}{ 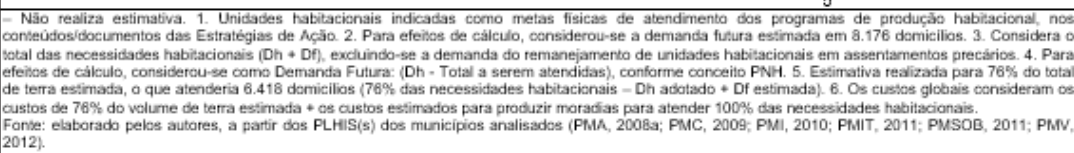 } \\
\hline
\end{tabular}

Tabela 4 - Estimativa de custos para atendimento das necessidades e demandas habitacionais. Fonte: Elaborado pelos autores.

das tributárias superiores a 50\% de seu valor venal (PMIT, 2001a). Considerando a disponibilidade de terra pública e a intenção de obtenção dos terrenos com dívida ativa, o PLHIS calcula custos apenas para o volume de terras que precisa ser adquirido. Esse volume representa $76 \%$ do total de terras estimadas para o atendimento do déficit acumulado e da demanda futura por novas moradias.

Santa Bárbara d'Oeste, por sua vez, não considerou como problemática do PLHIS o total de seu déficit habitacional e, portanto, realiza a estimativa de terra e custos apenas para os domicílios previstos para serem atendidos. Esses domicílios representam 70\% do déficit habitacional e não incluem o déficit quantitativo correspondente ao 
ônus excessivo com aluguel e à demanda futura situada nas faixas de renda entre três e cinco salários mínimos.

A estimativa de terras no PLHIS de Santa Bárbara não representa, portanto, as necessidades fundiárias das demandas a serem atendidas, já que os $\mathrm{R} \$ 97$ milhões calculados para atender à demanda dos 9.026 domicílios cobririam somente 4.513 domicílios, o que significa o enfrentamento de apenas $43 \%$ do déficit habitacional acumulado.

A estimativa das necessidades fundiárias no PLHIS de Itatiba não considera a demanda do déficit em assentamentos precários cuja ação de intervenção é o remanejamento de unidades habitacionais. Por tal aspecto, a estimativa de custos da terra exclui essa demanda, uma vez que ela será atendida na própria área do assentamento. Já a estimativa dos custos da produção volta a incluí-la, visto que há a necessidade da provisão de novos domicílios para seu atendimento. O mesmo ocorre no PLHIS de Campinas, a estimativa do volume global dos custos da produção compreende a demanda do remanejamento, as demais parcelas do déficit quantitativo e a demanda futura prioritária.

No caso do município de Indaiatuba, nota-se que o total de terra e custos estimado é menor do que o apresentado nos demais municípios, sobretudo do que em Americana, por exemplo, onde a demanda habitacional das estimativas é bem inferior. 
As decisões tomadas no processo de elaboração dos PLHIS(s) - tais como demandas habitacionais a serem atendidas, fração ideal de terra dos empreendimentos, tipologias de HIS, articulação de parâmetros com as legislações urbanísticas - configuram, portanto, o desenho das propostas de ação voltadas à aquisição de terras para a política de produção habitacional.

\section{Considerações finais}

Nos municípios de Americana, Campinas, Indaiatuba, Itatiba, Santa Bárbara d'Oeste e Valinhos, pertencentes à RMC, os cálculos de custos e estimativa de terra para HIS não foram dimensionados considerando o déficit estabelecido pelo $\mathrm{SNH}$. Dentre os seis municípios analisados, apenas Campinas e Itatiba incorporaram o conceito de necessidades habitacionais, o que significa que apenas esses dois conseguiriam tratar a questão fundiária considerando as demandas acumuladas (déficit) e futuras (demanda prioritária) por habitação. Americana, Indaiatuba e Santa Bárbara d'Oeste consideraram como necessidades habitacionais apenas as demandas previstas para serem atendidas pelas propostas de ação dos PLHIS. Valinhos, por sua vez, foi o único município que não considerou o conceito de necessidades habitacionais. Isso significa que, nesses últimos quatro municípios, tanto o volume de terra quanto o de recursos, assim como a delimitação de terras para 
HIS não foram estimados de forma suficiente para sanar o problema habitacional local, tornando frágil qualquer proposta de ação. Por outro lado, mesmo nos municípios que atenderam as diretrizes iniciais das necessidades habitacionais, diversas questões foram observadas no tocante à fragilidade da abordagem da questão fundiária. As inconsistências nas informações sobre a estimativa e terras e custos se fizeram presentes em todas as três categorias de análise adotadas para a leitura dos PLHIS(s).

As inconsistências do cálculo do déficit habitacional refletiram no cálculo da demanda fundiária e seus custos, repercutindo na distorção do enfrentamento final das necessidades habitacionais. As decisões sobre este enfrentamento partiram da própria tarefa de estimar o déficit habitacional, fundiário e os custos necessários à execução da política de produção de moradias na etapa de Diagnóstico Habitacional, em que se deveria apresentar uma leitura da realidade e não uma decisão estratégica de execução da política. Isso fez com que as indicações de terra, de recursos e as demandas a serem cobertas pelas ações do PLHIS(s), no processo posterior de formulação das Estratégias de Ação, tornassem-se ainda mais inconsistentes enquanto propostas de enfrentamento do problema. Se os municípios consideravam em seus diagnósticos estimativas que contemplavam o atendimento das demandas, nas estratégias de ação esse atendimento diminui ainda mais, colocando em xeque 
o papel do PLHIS enquanto um instrumento para definir medidas ao equacionamento dos problemas habitacionais. Em princípio, poder-se-ia afirmar que os PLHIS(s) revelariam uma possível incapacidade financeira ou fundiária dos níveis locais em atender seus déficits habitacionais, mas não que revelariam a exclusão precoce, por parte dos municípios, do enfrentamento de suas problemáticas.

Em relação às linhas de produção habitacional, as estratégias para sua viabilização se colocaram como parte financeira dos custos totais da moradia. Nessa perspectiva, os PLHIS(s) buscaram definir estratégias voltadas a diminuir o peso dos custos fundiários e com isso diminuir os recursos necessários para a produção habitacional, não onerando demasiadamente os cofres públicos. Os custos da terra chegam a impactar mais de $20 \%$ dos custos totais da produção de moradias e, em alguns casos, esse percentual acabaria por comprometer $1 \%$ de todo o orçamento público municipal.

A dificuldade ou ausência de controle do solo torna-se ainda mais nítida ao verificar que a preocupação dos PLHIS(s) em baratear os custos da terra se relaciona a uma preocupação de diminuir os custos da produção ou diminuir os recursos de contrapartida municipal - o que revela uma lógica privada de se empreender uma política pública cujo viés deveria ser intervir para distribuir e não somente procurar alternativas que busquem contornar um problema. 
O próprio fato dos municípios se ausentarem em assumir maiores responsabilidades na aplicação dos recursos previstos para a produção habitacional revela a intenção em se ausentar no maior controle do uso do solo e no enfrentamento da problemática da valorização fundiária, a qual se mostra custosa aos cofres públicos.

A presente pesquisa distingue as limitações do PLHIS como um instrumento para a concretização de um planejamento habitacional e traz uma contribuição a respeito dos investimentos públicos relativos às estimativas de terra $\mathrm{e}$ de custos em municípios da RMC, explicitando o distanciamento com a formulação de uma política fundiária eficaz.

Facilitar o acesso à terra e baratear o custo da habitação para a implementação de políticas públicas são metas fundamentais para viabilizar o desenvolvimento urbano democrático. No entanto, as metodologias de construção dos déficits habitacionais, da demanda fundiária e dos cálculos de custos devem ser alinhadas para que esse enfrentamento seja consistente e efetivo e não um contrassenso. Caso contrário, os PLHIS serão peças regulatórias fragilizadas antes mesmo de serem implementados. 


\section{Referências}

AVILA, P.C. (2006). Urban Land Use Regulations in Brazil: Land Market Impacts and Access to Housing. Lincoln Institute-World Bank. Disponível em: http://www.chs.ubc.ca/consortia/courses/library/DowallBrazil_Urban_Land_Housing_Markets-2006.pdf. Acesso em abril 2016.

AZEVEDO, S. de. (2007) Desafios da Habitação Popular no Brasil: políticas recentes e tendências. In: CARDOSO, Adauto Lúcio (Org.). Habitação social nas metrópoles brasileiras: uma avaliação das políticas habitacionais em Belém, Belo Horizonte, Porto Alegre, Recife, Rio de Janeiro e São Paulo no final do século XX. Porto Alegre: ANTAC, p. 1241.

CARDOSO, A. L. (2011) Habitação de Interesse Social: política ou mercado? Reflexos sobre a construção do espaço metropolitano. XIV Encontro Nacional da ANPUR, Rio de Janeiro. Disponível em: http:// www.observatoriodasmetropoles.net/download/adauto_cardoso.pdf. Acesso em maio 2016.

BONDUKI, N. (2008) Política habitacional e inclusão social no Brasil: revisão histórica e novas perspectivas no governo Lula. Revista eletrônica de Arquitetura e Urbanismo, São Paulo, n. 1, p. 70-104. Disponível em: http://www.usjt.br/arq.urb/numero_01/artigo_05_180908. pdf. Acesso em março 2016.

BRASIL. (2009) Ministério das Cidades. Plano Nacional de Habitação. Disponível em: http://www.cidades.gov.br/secretarias-nacionais/ secretaria-de-habitacao/politicanacional-de-habitacao/4PoliticaNaci onalHabitacao.pdf. Acesso em 10 janeiro 2016.

(2005) Ministério das Cidades. Sistema Nacional de Habita-

ção. Disponível em: http://www.cidades.gov.br/secretarias-nacionais/ secretaria-de-habitacao/politicanacional-de-habitacao/4PoliticaNacional Habitacao.pdf. Acesso em 10 janeiro 2016.

(2008) Ministério das Cidades. Planos Locais de Habitação de

Interesse Social - EAD-PLHIS. Brasília: Ministério das Cidades. 


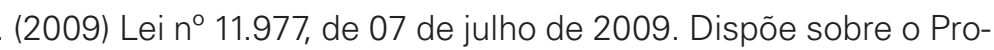
grama Minha Casa, Minha Vida - PMCMV e a regularização fundiária de assentamentos localizados em áreas urbanas. Diário Oficial da União, Brasília-DF, 08 jul. Disponível em: http://www.planalto.gov.br/ccivil_03/_ ato2007-2010/2009/lei/l11977.htm. Acesso em 04 fevereiro 2016.

CEF, Caixa Econômica Federal. (2009) Minha Casa, Minha Vida: moradia para as famílias, renda aos trabalhadores, desenvolvimento para o Brasil. Brasília: Caixa Econômica Federal. Disponível em: http:// www.adh.pi.gov.br/minha_casa_minha_vida.pdf. Acesso em 04 fevereiro 2016.

DENALDI, R. (2013a) Panorama da política habitacional no Brasil a partir de uma leitura regionalizada dos recentes planos locais de habitação de interesse social (PLHIS) elaborados no país. In: XV Encontro Nacional da ANPUR. Recife. Anais... Recife: Associação Nacional de Pós-Graduação e Pesquisa em Planejamento Urbano e Regional (ANPUR), p. 1-6.

(Org.). (2013b) Planejamento habitacional: notas sobre a precariedade e terra nos Planos Locais de Habitação. São Paulo: AnnaBlume.

Diagnóstico do setor habitacional. In: SANTA ROSA, Junia; DENALDI, Rosana (Org.). Curso à distância: Planos Locais de Habitação de Interesse Social. Brasília: Ministério das Cidades, 2009, p. 151-177

DENALDI, R.; LEITÃO, K.; AKAISHI, A. (2011) O recente processo de elaboração dos Planos Locais de Habitação de Interesse Social no Brasil: limitações e perspectivas. In: XIV Encontro Nacional da ANPUR, Rio de Janeiro. Anais... Rio de Janeiro: Associação Nacional de PósGraduação e Pesquisa em Planejamento Urbano e Regional. Disponível em: http://www.anpur.org.br/site/anais/ena14/ARQUIVOS/GT1-1-78420110111235517.pdf. Acesso em 26 abril 2016.

FERREIRA, J. S. W. (2005) A cidade para poucos: breve história da propriedade urbana no Brasil. In: Simpósio Interfaces das representações urbanas em tempos de globalização, 2005, Bauru-SP. Anais... Bauru-SP: Universidade Estadual Paulista- UNESP-Bauru; SESC-Bauru. Disponível 
em: http://cidadesparaquem.org/textos-acadmicos/2005/8/21/a-cidadepara-poucos-breve-histria-da-propriedade-urbana-no-brasil. Acesso em abril 2016.

MCIDADES, MINISTÉRIO DAS CIDADES. Plano Nacional de Habitação. Versão para debates. Brasília: Ministério das Cidades/Secretaria Nacional de Habitação, 2010. Disponível em: <http://www.cidades.gov. br/images/stories/ArquivosSNH/ArquivosPDF/Publica coes/Publiicacao_PlanHab_Capa.pdf>. Acesso em: 30 mar. 2016.

Guia de Adesão ao Sistema Nacional de Habitação de Interesse Social - SNHIS. Brasília: Ministério das Cidades/Secretaria Nacional de Habitação, 2008. Disponível em: < http://www.cidades.gov.br/ index.php/sistema-nacionalde-habitacao-de-interesse-social-snhis/754guia-de-adesao-ao-snhis>. Acesso em 04 abr. 2016.

MARICATO, E. (2006) O Ministério das Cidades e a Política Nacional de Desenvolvimento Urbano. São Paulo: IPEA.

MOREIRA, T. A. (2009) The National Housing Project and The new National Housing Policies in Brazil: proposals and advances for the right of housing. Jornal for Housing Science, v. 33, n. 2, pp. 89-98.

MOREIRA, T. A.; RIBEIRO, J. A, Z. M. T. (2016) A questão fundiária brasileira no desenho das políticas nacionais de habitação: considerações a partir do início do século XXI. Cadernos Metrópoles, v. 18, n. 35, p. 15-31.

PMA, Prefeitura Municipal de Americana. (2008a) Plano Local de Habitação de Interesse Social de Americana-SP: Produto 2. Diagnóstico Técnico. Americana-SP: Prefeitura Municipal de Americana/ Secretaria de Habitação e Desenvolvimento Urbano/ Cooperativa Integra.

(2008b) Plano Local de Habitação de Interesse Social de

Americana-SP: Produto 3. Plano Local de Habitação de Interesse Social do Município de Americana. Americana-SP: Prefeitura Municipal de Americana/ Secretaria de Habitação e Desenvolvimento Urbano/ Cooperativa Integra. 
PMC, Prefeitura Municipal de Campinas. (2011) Plano Municipal de Habitação de Campinas. Campinas: Prefeitura Municipal de Campinas / Secretaria de Habitação. Disponível em: http://2009.campinas. sp.gov.br/bibjuri/planohabitacao-2012.pdf. Acesso em 29 out. 2015.

PMI, Prefeitura Municipal de Indaiatuba. (2010a) Plano Local de Habitação de Interesse Social de Indaiatuba - PLHIS. Indaiatuba-SP: Prefeitura Municipal de Indaiatuba / Objetiva Administração de Negócios Ltda.

(2010a) Lei Complementar nº 09 de 22 de outubro de 2010. Dispõe sobre a revisão e consolidação da Lei no 4.067, de 24 de setembro de 2001, que dispõe sobre a instituição do Plano Diretor do Município de Indaiatuba - PDI e dá outras providências. Imprensa Oficial, Indaiatuba-SP, 28 out. Disponível em: http://www.camaraindaiatuba.sp.gov.br/ leis/arquivos/leicomplementar_09.PDF. Acesso em: 02 fevereiro 2016.

(2010c) Lei Complementar no 10 de 22 de outubro de 2010. Dispõe sobre a alteração, atualização, revisão e consolidação da lei $n^{\circ}$ 4.066, de 24 de setembro de 2001, que dispõe sobre o ordenamento do uso e da ocupação do solo do Município de Indaiatuba, e dá outras providências. Imprensa Oficial, Indaiatuba-SP, 28 out. Disponível em: http://www.camaraindaiatuba.sp.gov.br/leis/arquivos/leicomplementar_10.PDF. Acesso em: 02 fevereiro 2016.

PMIT, Prefeitura Municipal de Itatiba. (2011a) Plano Municipal de Habitação de Itatiba-SP: Relatório 2.2. Diagnóstico - versão revisada. Itatiba-SP: Prefeitura Municipal de Itatiba/ DEMACAMP.

(2011 b) Plano Municipal de Habitação de Itatiba-SP: Relatório

3.2. Estratégias de Ação - versão final. Itatiba-SP: Prefeitura Municipal de Itatiba/ DEMACAMP.

PMSBO, SANTA BÁRBARA D'OESTE. (2011) Lei n³.297, de 29 de junho de 2011. Autoriza o Poder Executivo adotar medidas visando à participação do Município no Sistema Nacional de Habitação de Interesse Social - SNHIS, aprova e institui o Plano Municipal de Habitação, cria o Fundo Municipal de Habitação de Interesse Social - FMHIS e institui o 
respectivo Conselho Gestor, dando outras providências. Diário Oficial do Município, Santa Bárbara d'Oeste-SP, 29 jun. Disponível em: http:// www.santabarbara.sp.gov.br/v4/index.php?pag=mostra\&dir=sec_de_ negocios_juridicos\&tabela=indiceleis\&id=6143. Acesso em: 05 março 2016.

PMV, Prefeitura Municipal de Valinhos. (2012) Plano Municipal de Habitação de Valinhos-SP. Valinhos-SP: Prefeitura Municipal de Valinhos. Disponível em: http://www.valinhos.sp.gov.br/portal/arquivos/desenvolvimento_social/PLHIS_Minuta_Final.pdf. Acesso em: 05 março 2016.

SANTA ROSA, J.; DENALDI, R. (2009). Curso à distância: Planos Locais de Habitação de Interesse Social. Brasília: Ministério das Cidades. Disponível em: http://www.cidades.gov.br/images/stories/ ArquivosSNH/ArquivosPDF/Livro_EAD-PLHIS_publicacao.pdf. Acesso em: 30 abril 2016. 
